\title{
SEXUALIDADE DA MULHER: DIFICULDADES, ENFRENTAMENTOS E ATUAÇÃO DOS SERVIÇOS DE SAÚDE
}

\author{
João Marcos Franco de Souza ${ }^{1}$, Kátia Terezinha Alves Rezende², \\ Larissa Aparecida Pedroso ${ }^{3}$ e Silvia Franco da Rocha Tonhom ${ }^{4}$ \\ 1,2,3,4 Faculdade de Medicina de Marilia (Famema), Brasil. 1 joaomarcosfs@famema.br, ${ }^{2}$ katialvesrezende@gmail.com, \\ 3lapedroso.Ip@gmail.com, , 4 siltonhom@gmail.com
}

\begin{abstract}
Resumo. Introdução: Existem dificuldades para a abordagem da sexualidade da mulher e elas dizem respeito aos profissionais, ao funcionamento dos serviços e às mulheres. Objetivos: Analisar as dificuldades encontradas pela mulher em relação à sexualidade ao longo da vida e como ela as enfrenta e analisar a atuação profissional frente às necessidades de saúde relacionadas à sexualidade nos serviços de atenção primária, na perspectiva das mulheres. Método: Trata-se de análise qualitativa, as participantes foram 24 mulheres atendidas nas USF e UBS, a entrevista semiestruturada foi o instrumento de coleta de dados e esses foram analisados pela análise de conteúdo, modalidade temática. Resultados: Esse processo permitiu definir dois temas, a saber as diferentes dificuldades relacionadas a sexualidade da mulher e atuação dos profissionais de saúde diante da sexualidade da mulher. Considerações Finais: A abordagem qualitativa possibilitou explicitar as necessidades da mulher e dos serviços de saúde no tocante a essa temática.
\end{abstract}

Palavras-chave: Sexualidade; Saúde da Mulher; Sexualidade Feminina; Atenção Básica

\section{WOMEN'S SEXUALITY: DIFFICULTIES, CONFRONTATIONS AND PERFORMANCE OF HEALTH SERVICES}

\begin{abstract}
Introduction: There are difficulties for the approach of women's sexuality and they refer to professionals, the functioning of services and to women. Objectives: Analyze the difficulties found by women regarding sexuality throughout their lives and how they face them and to analyze the professional performance towards the health needs related to sexuality in primary care services from the perspective of women. Method: It is a qualitative analysis, 24 women attended at the USF and UBS were the participants, the semi-structured interview was the instrument for data collection, which were analyzed by content analysis, thematic modality. Results: This process allowed us to define two themes, namely, the different difficulties related to women's sexuality and the approach of health professionals about women's sexuality. Final Considerations: The qualitative approach made it possible to show the needs of the women and of the services towards the theme.
\end{abstract}

Keywords: Sexuality; Women's Health; Female Sexuality; Primary Attention

\section{INTRODUÇÃO}

Compreender a sexualidade feminina como fenômeno complexo e determinante de saúde facilita a abordagem da mulher na perspectiva da integralidade, atuando nas dimensões biológica, psicológica e social da função sexual; contribuindo para que a mesma exponha e reflita suas potências e limites no que tange a sexualidade e defina estratégias de enfrentamento quando necessário (Lara, Scalco, Troncon \& Lopes, 2017).

Tal abordagem se faz ainda mais necessária atualmente, uma vez que as mudanças dos papeis da mulher na nossa sociedade, principalmente as relacionadas à inserção crescente 
no mercado de trabalho, ampliam sua autonomia e colocam em questão o ideal mulher-mãe. Uma vez que se dissocia a sexualidade de reprodução, as mulheres vislumbram outras perspectivas de vida e, assim, não se limitam única e exclusivamente ao que lhes é atribuído tradicionalmente (Machado \& Penna, 2016).

Então, tem-se que a abordagem da sexualidade possui como importante cenário a Atenção Primária à Saúde (APS), principalmente no contexto da saúde sexual e reprodutiva no Sistema Único de Saúde (SUS). Através da integração de tecnologias materiais de baixa complexidade e tecnologias de processo de alta complexidade, a APS, no que tange a sexualidade, procura atender demandas dos indivíduos e de outros setores, tendo, dessa forma, importância epidemiológica e de educação em saúde. Quanto à saúde sexual, é importante que ela seja entendida como não somente restrita à lógica reprodutiva e/ou à abordagem de pessoas com doenças sexualmente transmissíveis (DST), mas sim como área que enfoque a melhoria da qualidade de vida e das relações pessoais dos indivíduos (Nasser, Nemes, Andrade, Prado \& Castanheira, 2017).

E é nessa abordagem que a APS enfrenta desafios relacionados aos profissionais e funcionamento dos serviços - formação em saúde falha no que diz respeito ao tema; dificuldade por parte dos profissionais em abordar os usuários; ações básicas em saúde limitadas em seus conteúdos de saúde sexual - e também dificuldades por parte das próprias usuárias: vergonha, receio e pouca informação sobre o tema, por exemplo (Sanchez et al., 2013, Nasser et al., 2017)

Cientificamente, o recorte da sexualidade através do gênero se faz necessário, uma vez que o desenvolvimento da mesma varia empírica e teoricamente de acordo com ele, uma vez que homens e mulheres possuem expectativas distintas dos papeis sociais esperados para sua sexualidade. Além disso, ainda que o estudo da sexualidade da mulher ocorra, ele apresenta limitações, tendo pouco enfoque sociocultural, e mais em aspectos biológicos. Portanto, há a necessidade de as pesquisas serem originadas das vozes das mulheres, especificamente (Jen, 2017).

Nesse sentido, nossas perguntas de pesquisa são: A mulher apresenta dificuldades relacionadas a sexualidade ao longo da vida? Como a mulher enfrenta / lida com essas dificuldades? Como é a atuação dos serviços em relação à sexualidade da mulher? Assim, esse estudo pretende evidenciar as necessidades relacionadas a sexualidade da mulher para que os profissionais de saúde possam refletir sobre a relevância dessa abordagem. 
Além disso, a busca qualificada na base de dados nos mostrou que a literatura é escassa em relação a essa problemática. Nesse sentido, a pesquisa irá contribuir para ampliar o conhecimento sobre e mostrar a importância social da temática, possibilitando assim, repensar e reconstruir o cuidado em saúde.

\section{OBJETIVOS}

- Analisar as dificuldades encontradas pela mulher relacionadas à sexualidade ao longo da vida e como ela as enfrenta e

- Analisar a atuação profissional frente às necessidades de saúde relacionadas à sexualidade nos serviços de atenção primária na perspectiva das mulheres.

\section{METODOLOGIA}

Trata-se de uma pesquisa qualitativa, que pressupõe trabalhar com uma realidade que não pode ou não deveria ser quantificada, mas, sim, interpretada em seus motivos, significados, crenças, atitudes e valores. Entende-se, então, que para além de fazer parte da realidade social, a pesquisa qualitativa compreende as relações sociais em sua total complexidade (Minayo, 2016).

Para tal, no seguinte estudo, abordamos o cenário da Atenção Primária à Saúde de um município do interior paulista, que se organiza a partir de uma divisão em quatro regiões (norte, sul, leste e oeste), sendo que em cada uma delas existem tanto Unidades de Saúde da Família, quanto Unidades Básicas de Saúde.

Dessa forma, através de sorteio, serviram como cenários da pesquisa uma USF e uma UBS de cada região, totalizando oito serviços de Atenção Primária à Saúde. Definiu-se como critério de inclusão, mulheres acima de 18 anos, ter iniciado ou não a prática sexual e possuir vida ativa ou não. Como critério de exclusão, as menores de 18 anos, gestantes e mulheres que se encontravam no climatério. O instrumento de coleta de dados desse estudo se deu por meio de entrevista semiestruturada que combina perguntas fechadas e abertas, em que o entrevistado tem a possibilidade de discorrer sobre o tema em questão, sem se prender à indagação formulada (Minayo, 2016). 
O estudo foi aprovado em 21 de agosto de 2017, pelo Comitê de Ética em Pesquisa (CEP) sob o parecer de ํㅜㄹ 2.229.877 e Certificado de Apresentação para Apreciação Ética (CAAE): 71101817.9.0000.5413.

As mulheres foram abordadas pelos discentes enquanto esperavam pelo atendimento nas Unidades de Saúde. Os estudantes se identificaram e explicaram sobre a pesquisa e, assim, questionaram o desejo e a disponibilidade em participar. As participantes da investigação assinaram o Termo de Consentimento Livre e Esclarecido (TCLE).

As entrevistas foram realizadas por meio de um roteiro semiestruturado, o qual foi constituído de duas partes: A) Identificação da usuária do serviço de saúde: nome completo; idade; estado civil; religião; nível de escolaridade; ocupação e B) Questões norteadoras: 1. Apresentou dificuldades em relação a sua sexualidade? Se sim, quais foram? Como você enfrentou tais dificuldades? 2. Se mencionada a procura aos serviços de saúde na questão 1 , como foi realizado esse atendimento? Quais foram os profissionais envolvidos? Como foi a abordagem? Ficou satisfeita com o atendimento? Se sim ou se não, por quê? . 3. Se não mencionada a procura aos serviços de saúde na questão 1, 3.1 Questionar se procurou os serviços de saúde para enfrentar tais dificuldades. Se procurou, retornar a pergunta 2. 3.2 Se não procurou o serviço de saúde, por quê? 4. Na sua visão, os profissionais de saúde realizam um cuidado voltado à sexualidade da mulher? Se sim, de que forma / como? Se não, por quê?

Os dados foram coletados no período de quatro a 29 de junho de 2018. A priori foi definido um número de mulheres a serem entrevistadas em cada Unidade de Saúde, no entanto, atingiu-se a saturação com 24 entrevistas, ou seja, com o conteúdo obtido foi possível compreender a lógica interna do grupo de mulheres em relação ao objeto de estudo (Minayo, 2014). As entrevistas foram realizadas pelos pesquisadores e tiveram uma duração média de 25 minutos.

Para manter o sigilo dos(as) participantes do estudo e salvaguardar seus nomes, os discursos das participantes foram identificados com a letra $\mathrm{M}$ (mulher), seguida pelo número da entrevista.

A técnica de análise de dados empregada foi a Análise de Conteúdo, Modalidade Temática. A análise de conteúdo diz respeito a técnicas de pesquisa que permitem tornar replicáveis e 
válidas inferências sobre dados de um determinado contexto, por meio de procedimentos especializados e científicos. A análise de conteúdo parte de uma leitura de primeiro plano das falas, depoimentos e documentos, para atingir um nível mais profundo, ultrapassando os sentidos manifestos do material (Minayo, 2014). A análise temática está ligada a uma afirmação a respeito de determinado assunto. Fazer uma análise temática consiste em descobrir os núcleos do sentido que compõem uma comunicação, cuja presença ou frequência signifiquem algo para o objeto analítico visado.

Essa modalidade consiste em três etapas: Pré-Análise - escolha dos documentos a serem analisados e na retomada das hipóteses e dos objetivos iniciais da pesquisa; Exploração do material - operação classificatória que visa alcançar o núcleo de compreensão do texto, busca encontrar categorias que são expressões ou palavras significativas em função das quais o conteúdo de uma fala será organizado; Tratamento dos resultados obtidos e Interpretação - os resultados são submetidos a operações estatísticas simples ou complexas que permitem colocar em relevo as informações obtidas, a partir daí propõe inferências e realiza interpretações (Minayo, 2014).

De acordo com essa proposição, a transcrição das entrevistas e a leitura exaustiva do material permitiu a impregnação do conteúdo captado. Esse processo permitiu a identificação dos núcleos de sentido que consistiu no desdobramento de dois temas: as diferentes dificuldades relacionadas à sexualidade da mulher e atuação dos profissionais de saúde diante da sexualidade da mulher, conforme apresentado no quadro 1.

Quadro 1. Núcleos de Sentido articulados aos temas.

\begin{tabular}{|c|c|}
\hline Núcleos de Sentido & Temas \\
\hline $\begin{array}{l}\text { Inexperiência e desinformação influenciando a sexualidade da } \\
\text { mulher } \\
\text { A sexualidade da mulher dificultada pelas atitudes do parceiro } \\
\text { Causas orgânicas interferindo na sexualidade da mulher } \\
\text { Mulheres não apresentam dificuldades na prática sexual }\end{array}$ & $\begin{array}{c}\text { Tema 1: } \\
\text { As diferentes dificuldades } \\
\text { relacionadas a sexualidade da } \\
\text { mulher }\end{array}$ \\
\hline $\begin{array}{l}\text { O serviço de saúde lidando com as dificuldades relacionadas à } \\
\text { sexualidade: divergências entre as mulheres } \\
\text { Profissionais de Saúde capacitados para a abordagem } \\
\text { Nem todos profissionais de Saúde estão capacitados para a } \\
\text { abordagem } \\
\text { Profissionais de Saúde não estão capacitados para a } \\
\text { abordagem }\end{array}$ & $\begin{array}{c}\text { Tema 2: } \\
\text { Atuação dos profissionais de saúde } \\
\text { diante da sexualidade da mulher }\end{array}$ \\
\hline
\end{tabular}




\section{RESULTADOS}

\subsection{As mulheres}

Foram entrevistadas 24 mulheres. No tocante ao estado civil, dez $(41,66 \%)$ eram casadas, oito $(33,33 \%)$ solteiras, cinco $(20,85 \%)$ em união estável e uma $(4,16 \%)$ viúva. Em relação à idade, nove (37,51\%) mulheres se encontravam na faixa etária dos 19 a 29 anos, sete $(29,16 \%)$ na de 30 a 39 anos, seis (25\%) na de 40 a 49 anos e duas (8,33\%) na de 50 a 54 anos.

Quanto a escolaridade, uma $(4,16 \%)$ possuía o ensino fundamental incompleto, duas $(8,33 \%)$ ensino fundamental completo, três $(12,5 \%)$ ensino médio incompleto, dez $(41,66 \%)$ ensino médio completo, três (12,5\%) ensino superior incompleto e cinco $(20,85 \%)$ ensino superior completo.

No que se refere à religião, treze $(54,16 \%)$ eram católicas, oito $(33,33 \%)$ evangélicas, uma $(4,16 \%)$ considerava-se cristãs, uma (4,16\%) espiritualistas e uma $(4,16 \%)$ não possuía religião. Em relação a ocupação, 11 mulheres (45,83\%) eram portadoras de Carteira de Trabalho assinada, seis $(25,92 \%)$ eram profissionais liberais, uma $(4,16 \%)$ era estudante, uma $(4,16 \%)$ aposentada, uma $(4,16 \%)$ do lar e três $(12,5 \%)$ estavam desempregadas no momento.

\subsection{Os Temas}

No processamento dos dados foram identificados oito núcleos de sentido que foram agrupados em dois temas, a saber, as diferentes dificuldades relacionadas a sexualidade da mulher e atuação dos profissionais de saúde diante da sexualidade feminina.

\subsubsection{As diferentes dificuldades relacionadas a sexualidade da mulher}

A dor durante a prática sexual foi ou é a principal dificuldade no que diz respeito à sexualidade da mulher. Elas referiram possuir mais dificuldades no início da vida sexual, com diminuição ou falta de libido devido a inexperiência e desinformação.

"Ah, não era bom, porque, assim, era uma coisa que tinha dor, eu não queria. É uma coisa que é assim: 'eu tenho que fazer, eu tenho que passar por isso." M7; 
"Primeiro porque machuca, dói e você não sabe por que você não está lubrificando direito. Você vai descobrindo depois o seu corpo, só que dói, é incômodo e ainda a gente pensa assim: 'por que as pessoas gostam tanto de fazer sexo se machuca?'. Daí depois você vai descobrindo." M10.

Algumas mulheres enfrentaram as dificuldades sozinhas e ou com os parceiros.

"Olha, com ele [antigo parceiro] eu fui levando. Depois eu quis separar, então eu separei e deixei isso pra mim. Aí quando eu conheci o meu atual esposo, aí essa vontade voltou." M1;

"Que nem eu falo, a mulher não é o sexo frágil. Pelo contrário, então eu sempre fui muito aberta pra essas coisas assim. Nunca conversei com ninguém, mas sempre fui esclarecida na minha mente. Eu fui esclarecendo minhas dúvidas sozinha [...] às vezes eu escutava uma falando uma coisa aqui, outra falando outra coisa ali, eu juntava, eu pesquisava. Na escola tinham aulas de sexualidade, de como você usa um preservativo, das doenças sexualmente transmissíveis, então a gente vai, a gente pega um livro". M6;

"Na verdade, eu sou bem sozinha nessas coisas, e meu marido também não entende muito do assunto."M12.

Outra mulher evidencia a inexperiência do parceiro:

"[primeira e única relação sexual] foi dolorido, porque rompe tudo e eu não consegui ficar muito tempo, porque eu senti muita dor, eu particularmente senti muita dor, mas ele também, ele não pratica essas coisas."M21.

\section{Evidencia-se a sexualidade das mulheres dificultada pelas atitudes do parceiro,} expressada por meio de agressões físicas e incompreensão sobre as singularidades da libido feminina.

"[...] Era um namoro muito abusivo [...] sentimental, de tudo, agressão física, aí foi que não deu certo, aí foi quando eu não sabia mais, eu não me reconhecia mais. [...] Porque antes de ir morar com ele, antes das atitudes dele, o que a gente fazia era gostoso, o sexo era gostoso, e aí depois que a gente foi morar junto, era insuportável, eu não tinha vontade de fazer, só que eu fazia obrigada." M13;

"Perdoar, às vezes você até perdoa [...] lá no fundinho, parece que fica aquele negócio ali cutucando, que ele te fez mal lá atrás. [...] me atingiu muito, porque ele falava assim: "não, você não precisa ter prazer."” M16.

As causas orgânicas também interferem na sexualidade da mulher, por exemplo, cirurgias e miomas.

"[...] na época da cirurgia eu praticava para fazer a vontade dele, mas depois eu falei pra ele que eu não sinto nada [...] mas foi muito difícil depois da cirurgia pra mim."M17;

"Que nem eu te falei, eu tenho mioma, então eu sentia muita dor, às vezes ele queria, eu tinha que fazer, na hora da dor eu tinha que fingir que estava tudo bem, mas depois eu ficava toda dolorida na 
barriga e no útero doía muito. Então, eu não ficava satisfeita, mas eu não podia mostrar para ele que eu não estava a fim, então ficava um clima meio assim, mas eu nunca falei. Eu não queria contrariar ele, ele vinha tão carinhoso, já trabalhava o dia inteiro, então eu fazia porque eu pensava: se não for comigo, ele vai procurar outra. Aí eu aceitava porque ele não tinha culpa de eu estar com dor, mas quando eu estava com muita dor mesmo eu falava."M19.

Percebe-se que, mesmo com uma causa orgânica aparente, a relação com o parceiro, bem como a dor são percepções comuns e semelhantes às demais mulheres.

Outras entrevistadas afirmam não ter apresentado dificuldades relacionadas a sexualidade.

"Não, não, vinha sempre no posto, sempre fiz meus exames, sempre fui assim. la ao médico de ano em ano, fazia meus exames certinho, sempre fiz." M15.

\subsubsection{Atuação profissionais de saúde diante da sexualidade da mulher}

Diante dos conflitos relacionados a sexualidade da mulher, o serviço de saúde foi procurado. Dessas, algumas consideraram que suas necessidades foram acolhidas.

"Então aí eu consultei com a nossa enfermeira, eu expliquei pra ela, aí ela falou pra eu usar um lubrificante, essas coisas [...] O atendimento é muito bom também." M8;

"Foi muito bom, então aquele (médico) que foi aposentado também me ajudou muito, que normalmente médico conversa, pergunta o que você está sentindo [...] ele me passou uns remédios, que eu tomei e a pomada. Ele pergunta como é que eu estou me sentindo, o que é que você tem, então a pessoa fala o que está sentindo, perguntam como é que você está na sua vida, na sua sexualidade é você que tem que falar, se não está bem na sua vida sexual."M17.

E outras apontaram que os profissionais de saúde têm dificuldades em reconhecer e cuidar de suas demandas.

"[...] tem pessoas que não lidam muito bem com isso, que você vai fazer a pergunta e meio que te responde vazio, acho que não sabe orientar corretamente." M9;

"Eu já falei com o doutor, e ele falou que era normal sentir dor. Foi o básico mesmo, que incomodava um pouco a dor, daí ele falou que é questão de você estar com muito prazer ou pouco prazer, mas que é comum a mulher sentir um pouco de dor."M11

Salienta-se que os profissionais de saúde estão capacitados para abordar a sexualidade da mulher, porém elas precisam levar suas necessidades para os serviços. Explicitam a dificuldade da mulher falar sobre sexualidade. 
"É porque assim, você tem tudo que você precisa numa área de saúde, você pode chegar aqui e falar 'olha, eu preciso conversar ou com uma enfermeira, ou com uma médica mesmo, sobre umas dúvidas que eu tenho'." M7.

Destaca-se a importância de se ter segurança, confiança e liberdade para a mulher discorrer sobre sexualidade.

"eu acredito que vai se criando um ambiente de segurança, não é? Na conversa, por exemplo, te olha nos olhos, e te dá liberdade, confiança. Porque te passa uma confiança além do estudo, não é?"M7.

Por outro lado, aponta-se que nem todos os profissionais de saúde estão capacitados para abordar a sexualidade da mulher.

“Então eu acho que depende muito do profissional que você pega, daquilo que ele pode realmente fazer dentro das possibilidades que ele tem pra te ajudar. Ás vezes eu acho que falta... um pouquinho de ser humano mesmo não é?"M3;

"Tem alguns que estão, mas alguns não tão assim muito não, porque tem médico que quando tá atendendo o paciente não presta muita atenção no paciente, não conversa muito, só pergunta o que você tem e você vai falar aquilo e ele vai passar receita." M17;

Evidenciam que os profissionais de enfermagem estão qualificados para abordar as necessidades da mulher.

"A enfermeira que me atendeu na época ela foi ótima. O jeito profissional dela atender com sigilo, eu me sinto segura com o atendimento." $M 8$;

"Porque tem pessoas que não têm paciência pra lidar, não gosta que fica fazendo pergunta, só tá ali pra fazer o trabalho dela que é a rotina e pronto. Mas teve essa enfermeira, eu estou totalmente realizada com a prevenção que eu fiz, porque ela explicou tudo sobre sexualidade."M9.

Aparece também a oportunidade de dialogar sobre sexualidade com a psicóloga.

"Não sentia prazer em fazer nada e eu tinha medo de me relacionar de novo com alguém... então, eu acho que foi preciso a gente abordar (com a psicóloga), pra eu entender que aconteceu." M13.

Essas mulheres compreendem a consulta médica como sendo mais técnica e menos humanizada, reiterando a abordagem biomédica, ou seja, tratar somente as doenças, restringindo o cuidado. Essa prática dificulta a mulher a expor suas demandas.

“[...] o atendimento do médico, eu acho que é mais técnico. Não é tão humanizada [...] 'ai vamos tratar [...] tá doente?' vamos tratar a doença. " M8;

"Tem muitos que vivem no controle automático, tá ali só pra fazer o seu trabalho [...] a questão de médico, tem uns que perguntam só se tá bem, se tá com dor. Não pergunta se tá tendo algum problema 
na relação, acho que isso seria o ideal [...] tem muita mulher que quer falar, só que não tem voz, não tem oportunidade" M9.

As entrevistadas referem que os trabalhadores que não possuem habilidade para essa abordagem é devido a desmotivação com o trabalho e a superlotação dos serviços de saúde, a qual compromete o cuidado.

"E se você for ver ele na teoria, é dos sonhos, nenhum outro país tem um plano de saúde que nem o Brasil, que nem o SUS, ele é perfeito. Só que na prática, às vezes [...] não acontece. Só que eu acho que tem muita coisa no decorrer da sua trajetória, que vai te desmotivando."M3;

"No postinho, às vezes, tem pessoas que não dá muita atenção direito [...] Não dá muita atenção pra o que você tá querendo falar, conversar. [...] porque às vezes, tá cheio e tem muito serviço.” M4.

Ainda é apontada a dificuldade de entender a abordagem dos médicos.

"Eu acho também que a dificuldade está na forma como você fala, porque teve vezes que eu fui ao médico, saí de lá sem entender nada. Porque ele falou de uma forma que eu não conseguia compreender, e eu ficava com vergonha também de perguntar como que é, o que que foi, não entendia."M1.

Aparece também a necessidade de formar os profissionais com capacidade de dialogar, estabelecendo vínculo com a mulher para que a mesma possa expor suas necessidades relacionadas a sexualidade.

"Não sei se é falta de informação até entre os profissionais, porque tem muitos que a gente pergunta e não sabe explicar. Não perguntou o avançado, que seria sobre a vida da paciente, falta de vontade às vezes. [...] Eu acho que mais a conversa, porque você vai criar um vínculo com o paciente."M9.

Nesse sentido destaca-se que o vínculo, a cumplicidade e o sigilo profissional são essenciais para uma abordagem integral à sexualidade da mulher nos serviços de saúde.

"O vínculo de paciente com profissional pra mim. Eu tenho muito assim com a parte da enfermeira, mas do resto eu não me sinto segura, não me sinto à vontade também. [...] a questão da ética, de tirar dúvida, de saber que dali não vai sair nada."M8.

Apesar desse cenário, acredita-se que tem ocorrido mudanças, no que diz respeito a integralidade do cuidado, uma vez que os profissionais de saúde não devem se prender a tabus e preconceitos.

"Eu acho que tem mudado bastante [...] Então assim, se você olhar pra ele (paciente) como um todo, se você tiver essa visão como profissional, de às vezes enxergar além da queixa que ele te trouxe [...] não tem que estar preso a tabus, a preconceitos." M3. 
Dessa forma é imprescindível efetivar o cuidado em saúde a fim de que esse possa identificar as necessidades ocultadas e definir plano de intervenção.

"Vou dar um exemplo, uma paciente vem aqui, às vezes ela não tá só com aquele problema da sexualidade, às vezes o emocional dela está abalado, às vezes ela tá com depressão [...] tem que abranger tudo." M8.

Algumas entrevistadas declaram que dos profissionais de saúde não estão capacitados para abordar a sexualidade da mulher.

"tem pessoas que fazem aquilo porque gostam, tem gente que já faz porque, acho que é profissão, mas acho que, pra você ter uma profissão, você tem que fazer aquilo que você gosta [...] então mesma coisa na área da saúde, se for pra você sair da sua casa estressado, olhar pra cara do paciente, fazer uma receita e jogar lá, é melhor você nem fazer a faculdade [...] acho que tá muito déficit sabe? [...] conversar com o paciente, procurar saber o que tá acontecendo, escutar mais o paciente.” M6.

As mulheres apontam para a importância dessa abordagem nos serviços de saúde, mas que isso não ocorre devido a dificuldade de dialogar sobre o assunto.

"Eu acho que seria bom ter isso aqui dentro do posto de saúde, mas eu acho que as pessoas em si [...] tem dificuldade de conversar." $M 1$;

Outros aspectos a serem considerados a não abordagem da sexualidade junto a mulher é a organização e funcionamento dos serviços, como alta demanda de atendimentos, a qual compromete a comunicação entre os profissionais e usuários dos serviços de saúde.

"Você chegava lá tinha duzentas, trezentas pessoas pra serem atendidas, eles preferem mil vezes fazer um parto, fazer um pré-natal, do que explicar para as pessoas como funciona."M6.

E, por fim, os tabus que permeiam a sexualidade, tanto para os profissionais quanto para as pacientes, interferem na abordagem.

"Ele não te dá um espaço pra você falar 'não, eu vim aqui porque eu quero saber se é normal eu transar cinco vezes e não chegar ao orgasmo'. Você não tem isso, é um tabu, você não tem nem como entrar, aí você vai ficar até meio sem graça. Eu comecei a falar, ela já tipo cortou o assunto." M10.

\section{DISCUSSÃO}

A dor durante a prática sexual foi ou é a principal dificuldade no que diz respeito à sexualidade da mulher. Elas referiram possuir mais dificuldades no início da vida sexual, com diminuição ou falta de libido devido a inexperiência e desinformação. $E$, mais, que os obstáculos diante a sexualidade também estão relacionados a atitudes do parceiro e a presença de doenças. 
Sanchéz et al., 2013 indicam que por parte das pacientes, as dificuldades estão diretamente relacionadas ao medo de falar sobre sua privacidade sexual e serem julgadas por isso; medo de violação da confiabilidade; desinformação sexual com aspecto reducionista orgânico; negação da própria sexualidade; criação de barreiras que dificultam a comunicação e presença de terceiros no momento da consulta. Na nossa investigação também aparece a necessidade de se ter segurança, confiança e liberdade para a mulher discorrer sobre sexualidade com os profissionais de saúde.

As mulheres apontam para a importância da abordagem sobre sexualidade nos serviços de saúde e que mediante os conflitos relacionados a essa dimensão, algumas procuraram os profissionais. Algumas entrevistadas consideraram que suas necessidades foram acolhidas e outras apontaram que os profissionais de saúde têm limites em reconhecê-las.

No tocante às relações de sexualidade e gênero, Rodrigues, Nogueira, Higarashi, Heidemann e Baldissera (2019), evidenciam que por meio do diálogo, foi possível o afastamento da concepção doméstica das condutas femininas, ainda que durante toda a vida das participantes, a construção social tenha influenciado a sexualidade feminina de maneira conservadora e pautada nas relações de poder entre os gêneros.

As dificuldades para a abordagem da sexualidade, por parte dos profissionais, são decorrentes do baixo interesse pela temática sexualidade, tanto na graduação, quanto na educação continuada; conhecimentos sobre sexologia clínica escassos; medo / resistência consciente ou não de se aproximar do tema, visto ser um assunto tabu na cultura médica pelo receio de julgamentos por outros companheiros de trabalho; falta de habilidades para abordar aspectos íntimos e privados; reducionismo sexista; crença de que não existe recurso terapêutico eficaz para as disfunções sexuais; concepção de que elas são "normais para certas idades". Ainda que o déficit de formação dos profissionais persista, destaca-se, como principal razão para que esse tema não seja abordado, a falta de tempo nas consultas (Sanchéz et al., 2013).

Apesar de uma grande prevalência de disfunções sexuais entre as mulheres, a discussão sobre sexualidade entre médicos é limitada, sobretudo por causa de tabus e porque a abordagem sobre problemas sexuais é ineficiente para a maioria dos residentes em ginecologia e obstetrícia. E, mais, que existem poucos modelos para guiarem o médico na discussão sobre disfunção sexual e poucos protocolos disponíveis para o manejo de queixas sexuais orgânicas e não-orgânicas (Lara, Scalco, Troncon, \& Lopes, 2017). 
As entrevistadas indicam que a sexualidade não é abordada nos serviços devido a organização e funcionamento das unidades de saúde, como alta demanda de atendimentos, a qual compromete a comunicação entre os profissionais e usuários; os tabus que permeiam a sexualidade, tanto para os trabalhadores quanto para as mulheres, e, por fim a desmotivação com o trabalho.

Evidencia-se a escassez de noções de promoção de saúde na área, devido à, sobretudo, carência na formação sobre essa temática, o que deixa explícita, segundo os autores, a necessidade de se ampliar as discussões no meio acadêmico e profissional (Nogueira, Rodrigues, Labegalini, Lopes, \& Baldissera, 2017).

Para Lara, Scalco, Troncon e Lopes (2017) os profissionais de saúde deveriam incluir uma abordagem da sexualidade na sua rotina com as mulheres uma vez que os problemas sexuais são prevalentes, sobretudo em mulheres que procuram serviços da Atenção Primária. Segundo eles, uma história sexual deve se basear em: abordagem centrada na pessoa; recomendações baseadas em evidências para diagnóstico e tratamento e uso de abordagem unificada e gerenciada.

\section{CONSIDERAÇÕES FINAIS}

A investigação possibilitou analisar as dificuldades encontradas pelas mulheres relacionadas à sexualidade ao longo da vida e como elas as enfrentam, bem como analisar a atuação profissional frente às necessidades de saúde relacionadas à sexualidade nos serviços de atenção primária na perspectiva das mulheres, o que nos remete ao alcance dos objetivos propostos.

Em relação às diferentes dificuldades relacionadas à sexualidade, evidenciou-se a inexperiência e desinformação da mulher, a sexualidade da mulher dificultada pelas atitudes do parceiro e causas orgânicas interferindo. A respeito da atuação dos profissionais de saúde diante da sexualidade da mulher, constatou-se divergências entre as mulheres quanto ao acolhimento das dificuldades encontradas pelas mulheres e pelos trabalhadores e reconheceu-se dissenso quanto à capacitação dos mesmos.

A pesquisa reiterou que a sexualidade da mulher é um fenômeno complexo. Dessa forma, é fundamental que os profissionais de saúde abordem a temática, pois as mulheres possuem 
necessidades a serem acolhidas por eles. E, mais, que os entraves para uma efetiva atuação dos serviços de saúde decorrem da fragilidade do sistema de saúde público.

A abordagem qualitativa possibilitou explicitar os significados, as crenças, as atitudes e os valores da mulher em relação à sua sexualidade e algumas necessidades do serviço de saúde no tocante a essa temática. Ademais, a pesquisa, embora concernente a uma população adscrita, possibilitou revelar necessidades que podem contribuir para o planejamento de outros serviços de saúde na reorganização das ações direcionadas à essa população.

\section{REFERÊNCIAS}

Jen, S. (2017). Sexuality of midlife and older women: A review of theory use. Journal of Women \& Aging, 30 (3), 204-226.

Lara, L.A.S., Scalco, S.C.P., Troncon, J.K. \& Lopes, G.P. (2017). A model for the management of female sexual dysfunctions. Revista Brasileira de Ginecologia e Obstetrícia, 39 (4), 184-194.

Machado, J.S.A. \& Penna, C.M.M. (2016). Reprodução feminina e saúde sob os olhares de mulheres sem filhos. REME - Rev Min Enferm, 20, 1-7.

Minayo, M.C.S. (2014). O desafio do conhecimento: pesquisa qualitativa em saúde (14a ed.). São Paulo: Hucitec.

Minayo, M.C.S. (2016). Pesquisa social: teoria, método e criatividade (33a ed.). Petrópolis: Vozes.

Nasser, M.A., Nemes, M.I.B., Andrade, M.C., Prado, R.R., \& Castanheira, E.R.L. (2017). Assessment in the primary care of the State of São Paulo, Brazil: incipient actions in sexual and reproductive health. Revista de Saúde Pública, 51 (77), 1-12.

Nogueira, I.S., Rodrigues, D.M.M.R., Labegalini, C.M.G., Lopes, M.C.L. \& Baldissera, V.D.A. (2017). A percepção e formação dos acadêmicos de enfermagem acerca da sexualidade humana. Revista de pesquisa: Cuidado fundamental online, 9 (3), 614-619.

Rodrigues, D.M.M., Nogueira, I.S., Higarashi, I.H., Heidemann, I.T.S.B. \& Baldissera, V.D.A. (2019). Desvelamento crítico em sexualidade entre idosas como dispositivo de avaliação educattiva dialógica. Rev. Baiana Enferm., 33, 27754.

Sanchéz, F.S., Correales, R.G., López, A.R.J., Blanco, C.S.M., Hernandéz, R.M.M. \& Ubeda, M.J.T. (2013). La anamnesis em la história clínica em salud sexual: habilidades y actitudes. Semenger, 39 (8), 433-439.

Vieira, K.F.L., Nóbrega, R.P.M., Arruda, M.V.S. \& Veiga, P.M.M. (2016). Representação social das relações sexuais: um estudo transgeracional entre mulheres. Psicologia: Ciência e profissão, 36 (2), 329-340. 